\title{
中国工作母机产业发展研究
}

\author{
王否 ${ }^{1,2}$, 卢秉恒 ${ }^{1,2}$
}

（1. 西安交通大学高端制造装备协同创新中心，西安 710054；2. 西安增材制造国家研究院有限公司，西安 710300）

\begin{abstract}
摘要：工作母机在传统定义的各类机床的基础上, 还包括增材制造装备、增减材复合制造装备。开展以工作母机为代表的我 国高端制造装备产业发展战略研究，可拓宽智能制造路径，支撑制造强国建设。本文在系统分析全球工作母机产业链发展动 态及趋势、研判我国工作母机产业发展情况的基础上，对标世界先进水平，梳理出我国产业发展存在问题的具体领域: 超精 密机床基础研究和关键技术、大型机床加工精度和加工效率、国产机床整机性能可靠性和精度、先进增材制造工艺与复合制 造工艺装备的共性技术研发、高端工作母机智能化水平。面向 2035 年远期发展目标，突出 “十四五” 阶段性亟需，针对性 提出以重大设施制造工艺装备、超精密加工装备为代表的工作母机产业重点发展方向。研究建议：加强国家各类科技计划有 效衔接，注重国家政策配套及评价体系协同，组建以工作母机为代表的高端制造装备共性技术协同创新体系。
\end{abstract}

关键词: 工作母机；产业发展；重点方向；高端制造；数控装备

中图分类号：TH16 文献标识码：A

\section{Research on the Development of Machine Tool Industry in China}

\author{
Wang Lei ${ }^{1,2}$, Lu Bingheng ${ }^{1,2}$ \\ (1. Collaborative Innovation Center of High-End Manufacturing Equipment, Xi'an Jiaotong Univertsity, Xi'an 710054, China; \\ 2. National Institute Corporation of Additive Manufacturing, Xi'an 710300, China)
}

\begin{abstract}
This study focuses on the development of the high-end manufacturing equipment industry in China, represented by machine tools. The machine tool referred to herein includes not only the machine tools in traditional definition, such as lathes, milling machines, planers, drilling machines, boring machines, grinders, and gear making machines, but also additive manufacturing equipment and additive-subtractive hybrid manufacturing equipment. This study analyzes the development trends of the machine tool industry in China and the globe, and then studies the problems existing in China's machine tool industry. Compared with world's advanced level, China's machine tool industry still has weaknesses in (1) basic research and key technologies for ultra-precision machine tools, (2) the machining accuracy and efficiency of large-scale machine tools, (3) the reliability and accuracy retention of the whole machine performance, (4) the research and development of common technologies of the advanced additive manufacturing and hybrid manufacturing equipment, and (5) the level of intelligence of high-end machine tools. Furthermore, we propose the key direction of China's machine tool industry during the 14th Five-Year Plan and the following five to ten years, and put forward some policy measures for the development of machine tool industry in China, including coordinating national science and technology plans with national policy supporting and evaluation systems, and establishing and strengthening the common technology collaborative innovation system for the high-end manufacturing equipment represented by machine tools.
\end{abstract}

Keywords: machine tool; industrial development; key direction; high-end manufacturing; numerical control equipment

收稿日期 : 2019-12-25; 修回日期 : 2020-02-17

通讯作者: 王否, 西安交通大学高端制造装备协同创新中心副研究员, 研究方向为数控装备与智能制造; E-mail: wlei292@xjtu.edu.cn 资助项目：中国工程院咨询项目 “新兴产业发展战略研究（2035）”(2018-ZD-12)

本刊网址：www.engineering.org.cn/ch/journal/sscae 


\section{一、前言}

发展智能制造是我国制造强国建设的主攻方 向, 工作母机是发展智能制造的基础。工作母机以 高档数控机床为代表，具有基础性、通用性和战 略性; 在航空、航天、船舶、高精密仪器、车辆、 医疗器械等产业领域得到广泛应用, 处于制造业 价值链和产业链的核心环节。本文所指的工作母 机不仅包括传统定义的各类机床，如车床、铣床、 刨床、钻床、镗床、磨床、制齿机以及各类加工 中心，还包括增材制造（3D 打印）装备、增减 材复合制造装备。信息技术与制造技术的高度融 合, 推动了工作母机新的发展和创新。以工作母 机为标杆的智能制造装备, 融合了新一代人工智 能 $(\mathrm{AI})$ 、工业互联网、工业大数据等新兴技术, 被视为工业强国重塑制造业优势、抢占竞争制高 点的重要方向。

受智能制造技术应用、贸易争端变化、制造业 综合成本变化等因素的驱动, 全球制造业出现了大 迁移和局部调整的态势，进而推动了产业链、供应 链和价值链发生变化。在美国、日本、欧盟等工业 发达国家或地区，受技术创新衍生的价值红利的影 响, 跨国公司将制造业生产加速回流, 在注重控制 产业链高端环节的同时，推动将低端制造业向东南 亚、南亚、非洲等综合成本更为低廉的地区转移。 俄罗斯、巴西、印度和南非等新兴经济体正在快速 布局新技术开发和新兴产业发展，积极参与全球产 业再分工，承接产业及资本转移，拓展国际市场空 间。中国制造业处于 “前有截堵，后有追兵” 的不 利竞争局面, 制造供应链面临发展困境, 在谋求由 高速增长模式转向高质量发展、通过技术创新带动 产业升级方面存在迫切需求。

我国工作母机产业发展情况一直是国内相关 产业研究的重点内容。《中国机床产业发展蓝皮书 (2018)》分析了机床产业的国内外发展状况、技术 和产业发展趋势、重点应用领域的用户需求、主要 国家产业政策环境等。沈烈初 [1] 针对 “新一代智 能制造发展战略研究” 主题, 重点探讨了我国数控 机床与数控系统方面的问题与建议。陈惠仁 [2] 对 中国机床工业 40 年来的发展历史、当前问题和存 在差距进行了客观全面的评估分析。

当前, 世界经济增长乏力、我国汽车产业首次
出现年度负增长, 这不仅给以数控机床为代表的我 国工作母机市场带来了发展不确定性，还对制造装 备企业的投资和经营带来直接冲击。工作母机装备 产业作为智能制造的主战场，技术密集、资金密集、 人才密集的特征凸显, 需要开展深刻变革 [3]。为 此, 本文主要进行以工作母机为代表的高档数控机 床产业宏观发展研究, 分析产业国际国内发展形势, 研判产业发展存在问题，分阶段提出我国产业发展 的方向和建议。

\section{二、全球工作母机产业发展现状}

\section{（一）全球产业链竞争态势}

国际关系的发展和重构, 影响着全球制造业的 产业布局, 使得产业链竞争呈现出新态势。世界工业 大国纷纷制定并实施积极的产业发展战略。2019年 11 月，德国发布《国家工业战略 2030》, 目标是保 持德国工业在欧洲和全球市场竞争中的领先地位。 2019 年初, 美国发布《美国主导未来产业》, 明确 建议将 AI、先进制造业、量子信息科学和第五代 移动通信 $(5 \mathrm{G})$ 技术作为高端产业的四大领域。美 国产业链价值判断标准强调，必须确保美国控制和 引领全球产业链，尤其是在技术密集的高端装备制 造业保持绝对优势。

全球工作母机产业的发展大国和地区主要有美 国、中国、日本和以德国为代表的欧洲。根据赛迪 顾问统计，中国、日本和德国是机床的主要生产国 家。2019 年日本数控机床产业规模占全球比重约为 $32.1 \%$, 是全球第一大数控机床生产国。中国数控 机床产业规模略低于日本，占全球比重约为 31.5\%。 德国整体产业规模占全球比重约为 $17.2 \%$ 。然而, 全球高档数控机床龙头企业主要集中在德国、日本 和美国（见表 1)，日本山崎马扎克株式会社、德国 通快集团以及德日合资的德马吉森精机公司（DMG MORI）稳居行业龙头地位。

日本注重发展数控系统产业, 精密轴承、导轨 等关键功能部件产业, 高档数控机床核心机电、液 压、气动和光学元器件和整机产品, 先进刀具、测 量工具等，形成了具有全球竞争力的完整产业链。 欧洲机床制造商在专用机床、高技术以及定制解决 方案领域占据优势, 其中德国和瑞士重视发展数控 机床整机、关键功能部件以及高端配套部件的先进 
表 12019 年全球十大数控机床制造企业

\begin{tabular}{lccc}
\hline 排名 & 企业名称 & 国家 & 规模/亿美元 \\
\hline 1 & 山崎马扎克公司 & 日本 & 52.8 \\
2 & 通快公司 & 德国 & 42.4 \\
3 & 德马吉森精机公司 & 德国 & 38.2 \\
4 & 马格公司 & 美国 & 32.6 \\
5 & 天田公司 & 日本 & 31.1 \\
6 & 大隈公司 & 日本 & 19.4 \\
7 & 牧野公司 & 日本 & 18.8 \\
8 & 格劳博集团 & 德国 & 16.8 \\
9 & 哈斯公司 & 美国 & 14.8 \\
10 & 埃玛克公司 & 德国 & 8.7 \\
\hline
\end{tabular}

注: 数据来源于赛迪顾问统计。

性和实用性, 其整机产品和各种功能部件在质量、 性能上位居世界前列。美国在航空、航天、军工等 下游高端应用方面保持了持续创新能力, 仍处于世 界领先地位。中国则是世界最大的工作母机产销国 和进口国。受各国政策导向影响，全球高端装备制 造业竞争格局正在发生重大调整, 主要跨国装备企 业纷纷通过兼并收购、服务增值等方式，提升企业 核心竞争力。

全球增材制造产业的发展大国主要以美国、德 国、中国、日本和英国为代表，其中，中国、日 本和德国是增材制造设备的主要生产国家。根据 赛迪顾问统计，2019 年全球增材制造产业规模达 119.56 亿美元，增长率为 $29.9 \%$ 。其中，美国产业 规模占全球比重为 $40.4 \%$ ，是全球第一大增材制造 设备供应商; 德国是第二大增材制造设备供应商, 产业规模占全球比重为 $22.5 \%$; 中国整体产业规模 略低于德国, 占全球比重为 $18.6 \%$; 日本和英国分 别占全球产业规模的 $8.2 \%$ 和 $6.3 \%$ 。

瞄准国际竞争获取先发优势的目标，世界工业 大国或地区积极制定发展战略以推动先进制造业升 级, 对于高端装备产业采取了扶持和优先的策略。 欧洲机床工业合作委员会（CECIMO）提出，保持 未来欧洲机床产业竞争力的基础在于先进生产技 术、持续研发投资、缩短创新周期、高技能劳动力 等。美国国防部将 “先进机床与数控系统” 定为潜 在的技术发展领域，推动开展了下一代高档机床的 研究。美国国家科学技术委员会更新了《美国先进 制造领导战略》, 提出了 3 个方向的战略目标: 发 展和转化新的制造技术, 教育、培训制造业劳动力,
提升国内制造业供应链，细化了 3 个方面的技术性 内容, 即研发世界领先的材料和加工技术, 完善制 造业创新生态系统，加强国防制造业基础。

\section{（二）全球高档数控机床装备产业发展趋势}

当前, 高档数控机床技术朝着高速、高精度、 高可靠、功能复合、极端制造、绿色制造、网络化 和智能化的方向发展。发展智能数控机床、提高数 控机床装备产业的智能化水平，成为机床产业强国 的一致选择。美国、德国、日本等国在持续积累形 成技术优势的基础上，集中力量提升装备智能化水 平, 进而增强未来竞争能力。瑞典、瑞士、意大利、 西班牙和法国等国，因机床制造产业竞争力减弱, 中小机床行业（欧洲机床产业中的 $80 \%$ 由中小企 业组成) 正在开展数字化转型, 探索智能化解决 方案。

工业技术领域创新发展的主线体现为：数控机 床与新一代 AI 结合形成的智能机床, 以智能机床 为核心的智能制造单元, 结合机器人与控制等软硬 件形成的智能生产线、智能制造车间、智能制造工 厂、智能制造生态系统。此外，融合减材制造、增 材制造和激光加工等多功能为一体的复合加工机 床，对工作母机产业的发展带来深刻变化，已成为 全球机床产业发展的重要方向。

汽车产业是机床产业重要的下游产业, 也是中 高档金属切削机床的主要消费市场之一。世界各国 纷纷加速新能源汽车的普及和产能布局, 而依赖数 控系统制造的动力总成有可能是颠覆性的, 这将直 接影响机床产业的发展方向。全球航空制造产业对 
金属切削机床的需求量较大，但诸多企业都在面向 全球采取转包生产以解决产能问题, 也将间接影响 机床产业的分布格局。

\section{（三）全球增材制造装备产业发展趋势}

随着航空、航天、海洋、新能源及新能源汽车、 智能产品、高端医疗器械等领域对增材制造技术与 装备的需求趋于旺盛, 增材制造已经成为工业领域 的主流制造手段，进入了批量化应用阶段。这标志 着全球增材制造装备产业进入快速发展阶段。全球 增材制造产业的产值 2020 年有望达到 158 亿美元, 2022 年可升至 239 亿美元, 2024 年则有可能达到 356 亿美元 [4]。麦肯锡公司预测, 到 2025 年, 世界 增材制造产业的经济效益可达 2000 5000 亿美元 [5]。

工业强国纷纷加快增材制造产业布局。美国率 先将增材制造产业视为战略性产业, 2019 年市场 规模约为 48.3 亿美元。德国《国家工业战略 2030》 将增材制造列入未来重点发展的九大关键工业领 域。根据全球增材制造文献、专利以及装机量统计 数据, 全球增材制造产业已基本形成了以美国、欧 洲等发达国家和地区主导, 亚洲国家和地区后起追 赶的发展态势 [5]。

中国增材制造装备产业的技术应用发展速度 较快, 产业链已初具规模, 增材制造与传统制造 在诸多行业进行着深度结合。根据赛迪顾问统计, 2019 年中国增材制造产业规模达 157.47 亿元, 装 备产业规模为 70.86 亿元, 占比达到 $45 \%$ 。中国在 增材制造领域的专利、论文数量已经领先, 但在原 始创新和重大技术创新方面仍显薄弱。

\section{三、我国工作母机产业发展情况}

\section{（一）高档数控机床装备产业链}

“高档数控机床与基础制造装备”国家科技重 大专项（简称 04 专项）实施以来, 我国机床行业 取得了显著进展。机床行业实现了由普通机床为主 向数控机床为主、高档机床从无到有的重大转变, 初步建立了高档数控机床装备的完整产业链, 基本 实现了航空、航天、汽车等产业领域战略性需求的 自主可控。我国企业主持修订的 “S 试件” 国际标 准已获国际标准化组织 (ISO) 批准并正式发布, 实现了我国在高档数控机床检测领域国际标准 “零”
的突破。但由于市场需求变化和行业自身基础不 牢, 我国机床行业的结构失衡问题尚未完全消除。 对照 04 专项实施完毕后的状态来判断, 我国机床 行业与国际先进水平仍有 15 年左右的差距。

（1）自 2012 年起， 04 专项支持研发的高档型 数控系统已累计销售超过 2000 台 (套), 标准型数 控系统已累计销售超过 10 万台（套）; 但国内市场 亟需的高档数控与伺服驱动系统仍有 $90 \%$ 依靠进 口, 而高端基础部件 (如精密轴承、高精密光栅等) 仍是 “卡脖子” 问题。机床行业整机正向设计能力 仍有所缺乏, 针对用户需求定制的工艺研究以及相 应的整机、生产线设计能力更显不足。机床可靠性 和精度保持性技术还处于推广应用阶段, 数控系统、 伺服系统、精密光栅等核心元器件仍未形成连通配 套, 领域用户认可度不高。

（2）主要功能部件和关键零部件的发展水平有 了较大提升, 如高性能主轴单元、精密摆头、精密 回转工作台、光栅等测量反馈元件、自动换刀机构、 精密滚动导轨、精密丝杜单元、高精度轴承、液气 润滑装置等。但从产业链角度来看, 高端部件仍然 滞后于高档数控机床主机的发展需求, 如主要功能 单元和关键零部件 $90 \%$ 以上仍然依赖进口, 尤其 是电主轴、直线电机、主轴轴承和高精密光栅。

（3）在整机方面, 我国精密卧式加工中心等 30 多类重点产品达到了国际先进水平, 保障了国 家装备制造业的持续发展能力。在 04 专项支持下, 国产高档数控系统大规模进入航空、航天、兵器、 船舶等领域并开展示范应用。 $25 \mathrm{~m}$ 立柱移动立式铣 车床的技术参数、技术等级达到世界领先水平，体 现了我国高档数控重型机床的最高水平。但国产机 床的性能可靠性、精度保持性与国际先进水平相比 尚有不小差距。

(4) 在下游高档数控机床应用方面, 得益于汽 车、航空、航天、船舶、电力设备、工程机械等行 业的快速发展, 国产数控机床的生产量较大。通过 04 专项的引领和带动, 国产高档数控机床为核电、 大飞机等国家重大专项和重点工程提供了关键制造 装备, 解决了相关领域所需关键装备的 “有无问 题”, 实现了多项关键技术和装备的突破。例如, 航天领域建立了多条采用国产数控装备的示范生产 线, 实现 “备胎转正” 性的规模化应用; 汽车大型 覆盖件高效自动冲压生产线达到国际领先水平, 全 
球市场占有率超过 $40 \%$ 。然而, 国内的汽车动力总 成制造装备的产业化配套能力与国际领先水平仍然 有较大差距, $80 \%$ 以上依赖设备进口; 航空发动机 等高端装备领域所需的高速精密及复合材料制造等 的工作母机仍然不能满足需求; 尚未形成应对新能 源汽车等热门行业的多样高效解决方案。

（5）国内数控机床市场出现了以外资企业本土 化为代表的新形势。随着国内数控机床产品替代进 口能力的不断提升, 同时受政策、市场、成本、竞 争四大因素影响, 纯进口设备的比例正在减小。面 对中国巨大的市场需求，本土化成为外资企业参与 中国市场竞争的主要方式。大批跨国机床企业进入 中国, 加快实施制造和营销的本土化, 甚至建设世 界最大工厂、反向供应全球市场。例如, 德国埃马 克集团金坛工厂 2018 年生产机床超过 600 台, 供 应范围覆盖中国、欧洲、美国、日本等市场。

\section{（二）高档数控机床装备产业集群}

我国数控机床产业凭借全球最大的市场、研发、 制造和供应体系, 形成了从材料、功能部件、整机、 现代服务体系到诸多领域应用覆盖的完整产业生态 链。目前, 珠江三角洲地区、环渤海地区、长江三 角洲地区、西北地区等四大产业集群趋于形成, 重 点省市包括: 辽宁、山东、北京、上海、江苏、广东、 浙江、陕西。应对国家经济高质量发展要求, 数控 机床产业正在改变过去简单追求规模、数量和增长 速度的发展模式, 朝向高质量发展模式转变。

客观来看, 国内数控机床产业集群的发展水平 和发展质量不平衡问题较为突出, 亟待未来产业调 整和优化。受国际贸易争端、汽车产销量下滑等因 素的影响, 数控机床产业延续了低增长态势。一方 面, 国内机床企业发展出现分化, 部分企业因经营 模式盲目扩张等原因导致债务危机, 出现经营困局、 甚至破产重组; 而部分企业注重技术创新、市场深 耕, 抓住细分市场发展机会得以快速成长壮大。另 一方面, 部分外资企业扩大在华投资, 对产业集群 分布构成重大影响。

在我国四大机床产业集群内，机床企业竞争态 势形成了以技术实力雄厚的跨国企业组成的第一阵 营，以大型国有企业或国有控股企业和少数技术实 力较强的民营企业组成的第二阵营, 以及以大量技 术含量较低、规模较小的民营企业组成的第三阵营。
在当前经济增长速度放缓的形势下, 第二和第三阵 营面临行业洗牌的风险, 预计未来我国机床产业的 集中度将进一步提高。

\section{（三）增材制造装备}

得益于《增材制造产业发展行动计划（20172020 年)》的推动, 我国增材制造装备产业发展迅 速, 在产业创新能力、工艺技术和装备、关键零部 件配套、产业应用等环节的关键核心技术方面取得 了系列突破, 已成为飞机、运载火箭、舰船、核能 等战略领域的先进制造手段。我国初步建立了涵盖 增材制造金属材料、元器件、制造工艺、装备技术、 重大工程应用的全链条的技术创新体系, 整体技术 水平接近国际先进, 在部分领域达到国际先进。

整体来看, 我国增材制造领域相关专利和论文 数量已全球领先, 但在核心元器件、关键技术方面 存在短板, 原创技术缺乏, 特别是高光束质量激光 器、长寿命电子枪、高性能扫描振镜、阵列式高精 度微纳增材制造头等核心器件严重依赖进口。另外, 我国增材制造标准建设相对滞后, 在国际上话语权 不高。近年来的国际贸易摩擦更是凸显了我国增材 制造产业在原始创新、关键元器件等方面的薄弱环 节。后续应瞄准关键共性技术实施突破, 破解产 业发展中的 “卡脖子” 问题, 尽快实现产业关键 核心技术的自主可控, 从而把握产业创新和发展 的主动权。

我国已初步形成了以环渤海地区、长江三角 洲地区、珠江三角洲地区为核心, 中西部地区为纽 带的增材制造产业空间发展格局, 涌现出具有市场 竞争力的骨干企业, 形成了若干产业集聚区。长江 三角洲地区具备良好经济发展优势、区位条件和较 强的工业基础，已初步形成了包括增材制造材料制 备、装备生产、软件开发、应用服务及相关配套 服务的增材制造产业链。在珠江三角洲地区, 随 着粤港澳大湾区建设的推进，增材制造产业将得 到进一步集聚。中西部地区, 如陕西、湖北、湖 南等省份成为我国增材制造技术和产业化的重要 发展区域。

\section{四、我国工作母机产业面临的问题}

我国工作母机产业尽管在战略需求领域已经初 
步形成了自主保障能力, 但是在高端数控机床方面 整体竞争能力不强、产业规模化程度低、技术创新 能力薄弱, 高端产品对外依存度仍然较高。我国中 档数控机床国产化率为 $60 \%$, 国产高档数控系统的 市场占有率不到 $15 \%$ 。在下游行业应用领域, 大部 分精加工数控机床仍依赖于进口。机床产业整体上 与先进国家的差距大为缩小, 但国产机床的加工效 率、可靠性、精度和使用寿命等与世界先进水平还 有差距。我国机床产业整体上仍然处于全球产业价 值链的中低端, 缺乏有国际竞争力的企业及产品。

我国工作母机产业的自身基础不牢，面临激烈 的市场竞争，特别是高档数控机床面临市场化机制 失灵的竞争形态。我国数控机床在正向设计、基础 共性技术、产业前沿技术研究方面, 与世界先进水 平的差距呈现进一步扩大的趋势。为满足高质量、 高可靠性、低成本的制造目标, 我国机床产业对于 数控系统及核心数控装备的依赖程度趋于提升; 而 目前相关核心元器件、关键工业软件、高档数控系 统、高端功能部件及其制造装备依赖进口, 严重制 约了国产高性能装备的设计和制造水平。整体上, 我国高端数控加工装备距离世界先进水平大概存在 10 15 年的差距。在增材制造装备的技术方面, 我 国整体上处于跟跑状态, 增材制造装备产业化发展 势头良好, 但受限于核心器件及专用软件的薄弱, 我国高档增材制造装备, 特备是高性能金属增材制 造整机装备相比世界先进水平具有一定的差距, 装 备的质量、性能和稳定性仍待提升。

我国工作母机产业面临的发展问题主要表现在 以下几个方面。

（1）超精密机床基础研究和关键技术水平存 在差距。着眼国际先进, 超精密机床分辨率可达 $0.1 \mathrm{~nm}$, 定位精度可达 $1 \mathrm{~nm}$; 超精密镜头加工机床 生产的光学镜面型误差在纳米级, 高频粗䊁度约为 $0.1 \mathrm{~nm}$; 部分国家对超精密机床实行严格禁运和技 术封锁。相比之下, 我国超精密加工领域采用的机 床普遍于 20 多年前引进, 加工精度仅能达到亚微米, 精度相差 1 2 个数量级。由于无法满足产品研制的 需求, 我国高精度惯性器件等核心产品的性能相对 先进技术存在代差, 这成为我国高端装备发展面临 的重大瓶颈。

（2）大型机床的加工精度和加工效率存在差 距。国外先进的龙门铣床长达 $20 \mathrm{~m}$, 精度可达
$4 \mu \mathrm{m}$, 加工效率达到传统机床的 3 倍。国内普通机 床的加工利用率仅为 $15 \%$ 30\%, 加速度一般小于 $0.8 \mathrm{~g}$; 而国外普遍达到 60\% 90\%，加速度基本达 到 1 1.5 g。这使得国产多轴联动机床的轨迹精度和 加工效率始终未能取得明显改善。

（3）国产机床整机可靠性和精度保持性存在差 距。机床无故障运行时间短, 生产节奏不宜保持; 在机床全生命周期内的几何精度、主轴回转精度、 运动控制精度难以保证，且无数据支撑。这是制约 国产机床进入汽车动力总成生产线的主要瓶颈, 也 是制约国产机床行业市场竞争力提升的主要问题。

（4）先进增材制造工艺与复合制造工艺装备的 共性技术研发滞后。我国在增材制造方面缺少原始 技术创新, 装备发展基本是跟随状态, 产业规模小 且分散的情况较为突出, 高端大型装备进口受到限 制。在复合工艺制造方面, 车铣 / 镗铣等工序复合、 增减材工艺复合、冷热加工工艺复合、多能源驱动 等工艺装备是国际技术创新的主要方面, 但我国基 本上还处于单工序设备阶段, 相比世界先进水平具 有明显的差距。

(5) 高端工作母机智能化水平存在差距。国外 企业在新产品开发过程中已经引入或初步实现了机 床的智能功能, 如智能制定加工工艺参数、加工过 程自主感知环境和工况变化进行自适应控制、通过 手机控制加工过程的安全性、热处理设备基于机器 学习功能智能地控制淬火和退火的时间以保证所需 性能等。国内智能数控系统尚处于起步开发阶段, 距离投产应用尚有不小的距离。

（6）工作母机装备创新能力和产业生态亟待提 升。在产业集群内, 高档数控机床产业价值链高端 缺位, 产业共性技术投入缺位; 产业发展陷入中低 端, 缺少专精特配套企业。国内工作母机产业上下 游企业之间未能形成良好的合作关系，不利于产业 整体升级, 军民装备共享机制也有待完善。国内尚 未建立智能制造装备标准体系, 亟待健全高质量研 发人才培养体系、高技能技工人才培养和稳定就业 体系。

\section{五、工作母机产业发展重点方向}

智能制造正在快速发展, 以智能制造为引领的 全球制造业竞争加剧。围绕我国经济社会发展和国 
家安全的重大战略需求, 抓住新一轮科技革命和产 业变革的机遇，着力解决关键领域的 “卡脖子” 问 题。我国工作母机装备产业通过整体竞争力的大幅 提高, 在高端机床装备领域跻身国际发展前沿, 构 建产业竞争比较优势, 支撑制造强国战略目标。

\section{(一) 发展目标}

1. “十四五”发展目标

以高档数控机床为代表的工作母机装备系列产 品国际竞争力明显提高, 解决一批高档数控机床的 数控系统、关键功能部件制造的 “卡脖子” 问题, 研发一批重点领域亟需的工作母机装备。高度重视 各工业领域的工作母机、生产线的智能化改造, 实 施规模化验证, 提升工作母机的智能化水平, 促进 行业的市场开拓及高速发展。

到 2025 年, 核心元器件和材料基本实现国内 供应, 形成国产高档数控机床完整的产业发展链; 基本满足航空、航天、海工、国防以及新能源汽车 领域的重点需求，启动国产新一代信息电子制造装 备的攻关研制。增材制造在国产重大装备中实现工 程化应用, 成为大型复杂关键构件的重要制造手段。

\section{2035 年发展目标}

我国步入工作母机装备先进国家行列。以国产 高档数控机床为主体的成套成组装备, 支撑智能工 厂建设, 形成行业级解决方案, 助力诸多重大装备 领域的创新发展, 支持制造业装备的换代升级, 保 障制造强国目标的实现。

\section{（二）发展方向}

1. 航空、航天和航空发动机制造工艺装备

在宇航及深空探测制造装备方面, 解决新一代 中型、大型运载火箭量产对成套装备的亟需, 突破 飞行器大型构件和复杂构件批量高效精密制造的技 术瓶颈, 满足深空探测飞行器对复杂构件轻量化、 结构功能一体化的重大需求。

在大型飞机制造装备方面，突破大尺寸钛合金、 碳纤维复合材料以及异性材料叠层的航空结构件高 速切削、增减材复合以及大部件高精度互换性制造 等技术问题, 实现航空装备的高性能、高精度、高 效率、低成本制造。

在航空发动机制造装备方面, 产业化推广发动
机典型部件制造的国产化装备，突破航空发动机关 键零部件高温合金、高强度合金、复合材料的集成 设计制造、高效和高精制造技术瓶颈，解决进口依 赖问题。

\section{2. 新型舰船及深海探测制造工艺装备}

继续完善船舶及海工大型柴油机缸体、曲轴、 齿轮和船用燃气轮机叶片、浴轮轴、叶盘等先进成 套技术装备。突破大型舰船关键部件制造技术、大 型船用螺旋桨推进器整机加工装备、深海焊接 / 探 测及深海工作站制造装备等，推进舰船增材制造现 场维修成套装备发展, 实现关键装备自主可控。

3. 轨道交通车辆和新能源汽车关键零部件加工 成套装备及生产线

针对动车组车体、客车车体等大型复杂型面加 工需求, 研制智能磨抛系统和柔性打磨工具; 针对 转向架、变速箱、轮对等关键零组件制造需求, 开 发专用高效加工成套装备及生产线。重点开发新能 源汽车变速箱高效加工、近净成形装备及成组工艺 生产线, 研制高效加工与成形、在线检测与装配成 套装备及生产线。

\section{4. 国家重点领域亟需的超精密加工装备}

超精密加工技术是军民领域高端装备制造的核 心技术，超精密机床是实现超精密加工的基础。面 向新一代惯性仪表制造、多目标红外探测及高精度 智能导引等领域亟需, 集中优势力量快速突破超精 密加工机床技术瓶颈，推动超精密制造领域相关基 础理论、测量技术、超精密机床制造技术、在线测 量与智能控制技术的重大发展。探索形成超精密加 工及高端机床自主研发的高效创新模式。

\section{六、对策建议}

瞄准 2035 年建成科技强国的战略目标, 围绕 战略新兴产业发展对工作母机装备的亟需, 发挥社 会主义市场经济条件下关键核心技术攻关新型举国 体制的优势, 壮大以工作母机为代表的高端装备产 业，为制造强国战略实施提供基础和保障。产业发 展过程中, 有效打破行业壁垒, 充分引入市场竞争, 打牢国家大工业基础, 以产品配套能力、价值链和 创新链为中心, 重构军民装备融合发展的产业体系, 实现社会化配套。 


\section{(一) 国家各类科技计划有效衔接}

结合工作母机产业发展特征, 完善对基础性、 战略性、前沿性科学研究和共性技术的支持机制, 实现国家各类科技计划的有效衔接。发挥国家自然 科学基金在基础研究和原始创新研究方面的引导和 支持作用, 倡导先进工艺多学科交叉研究、母机装 备原始创新研究。相关原始创新研究的部署应接续 支持重点研发计划、科技重大专项，基础研究成果 应结合有关专项的攻关任务进行贯彻、扩散及融入。 重点研发计划的具体成果, 如样机、工艺等应在有 关专项中持续开展应用验证和推广示范。

建议启动 04 专项的接续计划, 延续我国高端 制造装备的创新发展节奏, 总体任务目标应从 “跟 跑” 转向 “并跑”。专项接续计划由探索领域重要 用户 (即业主) 牵头, 实行 “产学研用” 联合体大 平台协同攻关的新举国体制, 重点解决我国航空、 航天、军工、核能动力、信息产品、新能源汽车等 行业高端制造装备的自主可控和与时俱进的持续发 展能力。

将数控机床和基础制造装备（“铸锻焊”）研究 内容聚焦在高效、精密、可靠性和精度保持性方面, 进而拓展到超精密机床、大型复合材料制造装备、 大尺寸高效金属增材制造装备、冷热加工、宏微纳 结构制造、高能束工艺复合装备及制造装备智能化。 注重专项研究成果的产业和企业应用, 在配套政策 支持下, 进一步巩固创新成果、提升经济效益。

\section{（二）国家政策配套及评价体系协同}

优化国家科技成果采购体系, 将各类科技成果 编制目录简介进行宣传推广。国资企业技改采购应 优先使用国家科技成果、优先采购国产高端装备, 或者确定一定比例对成果产品实现税费补贴, 切实 减轻制造业企业的负担和经营成本。改革调整企 业涉费比例, 降低公共服务价格, 探索新的制造 业融资方式，引导金融机构降低制造业企业的融 资成本。制定优惠政策, 改变制造业企业留人难、 人才流失的困境。

改革高等院校和职业院校的学科评估指标体 系, 在学科评估、人才选拔、人才培养的各项指标 方面, 倡导注重实效、解决亟需。通过科研实践培 养勇于创新、善于创新、献身实业的工程技术人才, 加强论文、专利等研究成果的工程化导向。针对制
造专业人才培养，在打牢基础、淡化专业的同时, 应加强智能制造传感器、软件及大数据等方面的知 识内容与研究实践。

\section{（三）构建以工作母机为代表的高端制造装备共性 技术协同创新体系}

我国高端制造装备产业的发展模式应由 “跟踪 引进吸收” 逐步向 “并行自主创新” 以及进一步 的 “原始创新领跑” 转变。进一步深化国家科技 体制改革, 针对航天、航空、军工等国家重大需求, 探索高端制造装备全产业链协同创新模式。梳理 核心技术、关键元器件、工艺和装备的的短板问 题以及 “缺链” “断链” 环节, 以高端制造装备协 同创新中心为基础组建 “产学研用” 联合体。组 织全产业链协同创新、技术攻关, 建立上游/中游 / 下游分工合作、利益共享的产业链组织新模式。

以正在建设的制造业创新中心为基础, 对现 有分散在高等院校和科研院所的国家重点实验室、 国家工程实验室、工程研究中心等进行优化重组, 建立 “产学研用” 长效合作机制, 形成分布式、 网络化的新型科研机构集群: 作为非盈利研究机 构, 为全国制造业企业特别是中小企业提供技术 支持, 填补以高等院校和科研院所为主体的基础 研究与以企业为主体的产品和产业技术创新之间 的鸿沟。

建议国家设立 “工作母机国家实验室”, 致力 于正向设计、关键元器件、大数据及智能技术使能 软件的研发, 形成基础研究、竞争前沿高技术研究 和社会公益研究的高端智力聚集地, 支撑工作母机 产业的长远发展及行业应用。

培养一批世界领先企业, 发挥 “龙头” 效应, 形成产业上下游协作配套能力, 带动产业竞争力的 整体跃升, 进而形成具有世界领先技术和持续创新 能力的产业集群。

引导竞争力不强的机床企业实施转型, 成为民 生领域或国防军工领域专用装备的提供商, 制造业 转型升级与智能化改造的领头羊, 制造业整体解决 方案的一体化供应商。

引导中小企业向 “专精特” 方向发展和成长, 通过税收优惠或金融支持鼓励其深耕基础零部件、 材料、元器件、传感器、各类工业软件、以及专用 装备等细分领域, 实现差异化发展。 


\section{参考文献}

[1] 沈烈初. 再论“新一代智能制造发展战略研究”——读“制造的 数字化网络化智能化的思考与建议”的启示 [J]. 中国仪器仪表, 2018 (4): 27-28.

Shen L C. Further discussion on the development strategy of the new generation of intelligent manufacturing $[\mathrm{J}]$. China Instruments, 2018 (4): 27-28.

[2] 陈惠仁. 中国机床工业40年 [J]. 经济导刊, 2019 (2): 42-52.

Chen H R. 40 years of China machine tool industry [J]. Economic Herald, 2019 (2): 42-52.

[3] 中国机床工具工业协会. CIMT2019: 全球机床工具行业发展的 最新风向标 [J]. 世界制造技术与装备市场, 2019, 161(2): 23-26. China Machine Tool Industry Association. CIMT2019: The latest wind vane of global machine tool industry development [J]. World Manufacturing Engineering \& Market, 2019, 161(2): 23-26.

[4] Wohlers Associates. Wohlers report 2019: 3D printing and additive manufacturing state of the industry $[\mathrm{R} / \mathrm{OL}]$. Fort Collins: Wohlers Associates, Inc. (2019-03-26) [2019-12-15]. http://wohlersassociates.com.

[5] 赛迪智库. 中国增材制造产业发展报告 (2017年) 解读[EB/ OL]. (2017-07-28) [2019-12-15]. https://www.sohu.com/ a/162128762_465915.

CCID Thinktank. Development report of China's additive manufacturing industry (2017) [EB/OL]. (2017-07-28) [2019-12-15]. https://www.sohu.com/a/162128762_465915. 